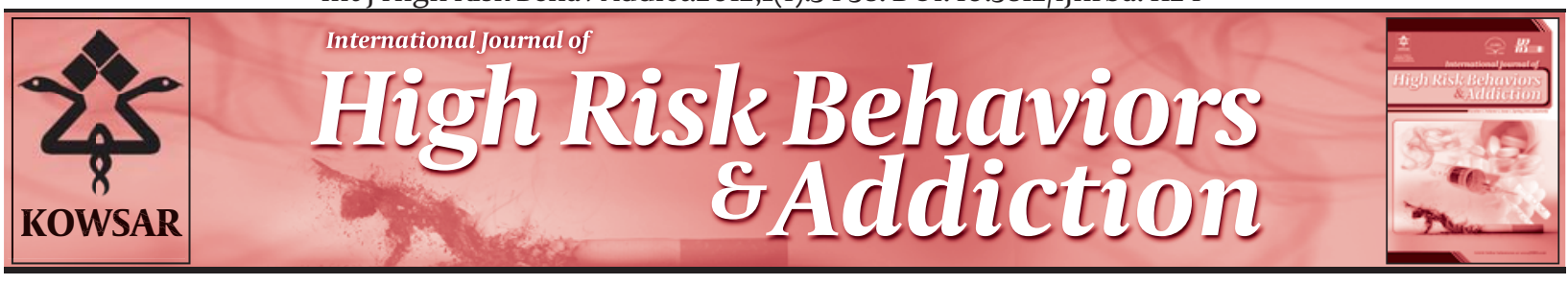

\title{
The Effectiveness of Lifestyle Training in Relapse Prevention and Resiliency Enhancement for People with Substance Dependency
}

\author{
Esa Jafari ${ }^{1}$, Mohsen Ahmadi ${ }^{2}$, Ali Mohammadzadeh ${ }^{3}$, Mahmood Najafi ${ }^{4}$ \\ ${ }^{1}$ Department of Psychology, Payam-e Noor University, Terhran Branch, Terhran, IR Iran \\ ${ }^{2}$ Department of Psychology, Islamic Azad University, Hamadan Branch, Hamadan, IR Iran \\ ${ }^{3}$ Department of Psychology, Payam-e Noor University, East Azerbaijan Branch, IR Iran \\ ${ }^{4}$ Department of Psychology, Semnan University, Semnan, IR Iran
}

\section{A R T I C L E I N F O \\ Article type: \\ Original Article \\ Article history: \\ Received: 07 Jul 2011 \\ Revised: 11 Sep 2011 \\ Accepted: 25 Nov 2011}

\section{Keywords:}

Lifestyle

Relapse

Resiliency

Substance Dependence

\begin{abstract}
A B S T R A C T
Background: Drug addiction is a complex disorder that incorporates multiple factors including those related to genetics, beliefs, unconscious processes, gender, and temperament as well as developmental, social, economic, and political factors. The present study investigates these factors.

Objectives: The aim of this study is to determine the effectiveness of lifestyle training in relapse prevention and resiliency enhancement in people with substance dependency. Patients and Methods: In a semi-experimental study, 26 subjects with a diagnosis of opiate use disorders in the Jameiate Aftab Center of Tehran who had successfully detoxified, were divided into two groups, an experimental group (12 subjects) and a control group (14 subjects). The participants were selected according to available sampling methods. The experimental group underwent 12 sessions of coping skills training while the control group did not receive any treatment. All subjects in the study were assessed by the Conner-Davidson Resiliency Scale (CD-RIS) and a test for morphine before treatment, after treatment, and at a 4-month follow-up stage. Data were analyzed using descriptive methods as well as t-test and ANCOVA analyses.

Results: The $\chi 2$ test showed that the experimental and control groups significantly differed in relapse rates $\left(\chi_{2}=6.30, \mathrm{df}=1, P<0.001\right)$. In addition, the covariance analysis showed a significant difference between the two groups in resiliency enhancement at post-test $(\mathrm{F}=33.76, P<0.001)$ and follow-up $(\mathrm{F}=37.67, P<0.001)$.

Conclusion: The results indicate that lifestyle training is effective in resiliency enhancement and relapse prevention for people with substance dependency.
\end{abstract}

Copyright $\odot 2012$ Kowsar Corp. All rights reserved.

\section{- Implication for health policy/practice/research/medical education:}

The findings of the present study can provide for a permanent psychological treatment after detoxification and used in psychology intervention and deterrent from relapse prevention in people that are in detoxification stage.

\section{- Please cite this paper as:}

Jafari E, Ahmadi M, Mohammadzadeh A, Najafi M. The Effectiveness of Lifestyle Training in Relapse Prevention and Resiliency Enhancement of People with Substance Dependency. Int J High Risk Behav Addict. 2012;1(1). 34-8. DOI:10.5812/ijhrba.4124

\section{Background}

Drug addiction is a complex disorder that incorporates multiple factors including those related to genetics, be-

\footnotetext{
* Corresponding author: Mohsen Ahmadi, Department of Psychology, Islamic Azad University, Hamadan Branch, Hamadan, IR Iran. Tel: +988114494155, Fax:+98-8114494155, E-mail: Mahmadi_1362@yahoo.com

DOI:10.5812/ijhrba.4124

Copyright $\odot 2012$ Kowsar Corp. All rights reserved.
}

liefs, unconscious processes, gender, and temperament as well as developmental, social, economic, and political factors (1). In this area, it is vital to have a theoretical framework that integrates biological, mental, and social perspectives to aid the assessment, conceptualization, and explanation of addictive behaviors. Such integration is also critical to the establishment of a theoretically grounded intervention. Carrol (2) suggests that the individual psychology and lifestyle approach proposed by 
Adler supports the use of such a theoretical framework in studying addiction.

Although substantial progress has been made in treating drug addiction, the existence of a relapse period is still a key problem (3). In spite of the attention and established special programs focusing on relapse prevention and recovery, the majority of clients do not permanently avoid drug use. Many factors are involved in the process of relapse after detoxification. Among these factors, lifestyle is critical for preventing them from reusing drugs. From a psychological perspective, many studies have been carried out concerning factors such as recovery, abstinece, and relapse reduction after detoxification. Such studies have shown that lifestyle management is one of the effective factors in the process of recovery and relapse prevention according to Marlatt and Gordon (4) individual lifestyle and patient background play key role in risk-taking behaviors with respect to drug use as well as resistance and relapse prevention. Clinical and research experience has shown that if client lifestyle via treatment after detoxification does not change, the behaviors may tend towards drug use due to the chronic and recurring quality of addiction. Changing the lifestyle can therefore prolong the period of drug avoidance (5). The studies conducted in this field indicate that the promotion of lifestyle has a significant effect on the process of drug avoidance and relapse (6-8). Such results show that lifestyle adjustments can facilitate the process of recovery. Lifestyle education programs help clients replace their old life with a new one through the use of correction, adjusted beliefs, and altered behaviors achieved during the instructional sessions. One of the variables considered in the area of drug abuse is resiliency. Resiliency means showing inner dispositional strength and using external support processes when encountering the effects of risk-creating factors. Kitano and Lewis (9) has defined resiliency as "returning back, elasticity, and returning to the original state after encountering failure and the problems such important changes in the family status, occupation, education, divorce, illness, and drug abuse." The resiliency literature shows that one of the factors causing resiliency is lifestyle and its components. Many have shown that lifestyle plays an important role in resiliency enhancement $(10,11)$. The research therefore suggests that lifestyle can be counted as an important factor in creating resiliency via factors such as knowing the most appropriate way of living and the factors affecting that path, self-understanding, spirituality, occupation, social relationships, and the recognition of one's primary mistakes. Consequently, enhancement resiliency via lifestyle factors serves as a shield for the prevention of drug abuse and reduces the likelihood of relapse. The high rate of relapse after detoxification suggests a need for effective psychological treatment. The present study attempts to address the shortage of research related to the effectiveness of psychological interventions such as lifestyle and its function in enhanced resiliency specifically, the present study attempts to determine whether lifestyle training is effective in preventing relapse and enhancing resiliency for individuals addicted to drugs.

\section{Objectives}

This study aimed to determine the effectiveness of lifestyle training in relapse prevention and resiliency enhancement for people with substance dependency.

\section{Patients and Methods}

A semi-experimental method was used to address the objective and the hypotheses of this study. The sample was drawn from addicted individuals referred to the Jameiate Aftab Center in Tehran who had finished the detoxification phase as of May 2009. Participation in the study was restricted to those who a) were between 18 and 40 years old, b) were diagnosed addicts according to the DSM-IV-TR, c) had been clinically interviewed by a psychiatrist, and d) had completed the detoxification period. Participants were also required to have negative urinalysis tests for drugs, to not be regularly taking antipsychotic medicines, to not have somatic or psychological problems, to not participate in any intervention while being studied, and to not be addicted to several drugs simultaneously. The final study sample of 26 men addicted to drugs was divided into two groups-one receiving lifestyle training and a control group receiving no training. We used the following data collection instruments.

\subsection{Morphine Test}

The absence of opium in the patient's urine was the criterion for not relapsing.

\subsection{Conner-Davidson Resilience Scale}

This scale was developed by Conner-Davidson (12) through a review of the resiliency literature from 1979 to 1991. This scale is believed to be effective in distinguishing the resilient from the non-resilient individuals in clinical groups. This assessment uses a Likert scale with choices ranging from "always wrong" to "always correct." The maximum score is 100 and the minimum score is 0 ; the cut-off point for individual without any mental disorder is 80.4 . It is 47.7 for people with PTST. This scale has been normalized for Iranians by Mohammadi (13). To determine the validity of the scale, the correlation coefficient for each choice and the total score was calculated. This was followed by a factorial analysis. With the exception of choice three, the correlation coefficient of each score and the total score was between 0.41 and 0.64 . The scale choices were then analyzed using a principle components analysis. Before extracting the factors based on the correlation matrix of the choices, two parameters of the KMO and Kruit-Bartlet tests were taken into account. The value of the KMO was 0.87 and the chi-square for the Kruit-Bartlet test was 5556.28. Both support the adequacy of the factorial analysis. Concerning scale reliability, Samani et al. (14) found a Cronbach's alpha of 0.87 using a 
sample of students. These studies show that the scale is both valid and reliable for clinical and nonclinical samples.

To conduct the study, 12 subjects were assigned to the experimental group and 14 subjects were assigned to the control group based on the negative morphine test and completion of the detoxification period as well as on the entry criteria. To gain the consent of the participants, we talked with them concerning the objectives, theme, method, and the scheduling of the sessions. Each of the twelve treatment sessions lasted 90 minutes, with a break provided at the midpoint of the session. The experimental group sessions were as follows.

- Session 1

Acquainting the clients with the therapist; pre-test administration

\section{- Session 2}

Client daily lifestyle awareness

\section{- Session 3}

Explanation of the lifestyle concept

\section{- Session 4}

The life story and its components such as pleasant and unpleasant experiences, important changes, the first life memory, important childhood memories from adolescence and youth, other memories, and the structure of important life events

\section{- Session 5}

Treating core life issues

\section{- Session 6}

Positive and negative effectiveness in life

\section{- Session 7}

Creating another story

\section{- Session 8}

Life priorities

\section{- Session 9}

Investigation of major life mistakes

\section{- Session 10}

Social interests and their effects on inter-personal relationships

\section{- Session 11}

Dealing with the other affairs of life such as love, occupation, the self, and its function in correcting lifestyle

\section{- Session 12}

Overview and summary of the sessions, the control group took part in 12 sessions but they did not receive any intervention or specific treatment for addiction. Instead, they participated in discussions concerning addiction and the way the people tend toward drugs use and the contrivances that should be abandoned. In the first session, for both groups, we discussed the sessions of each group, the objectives, the topic of discussion, and the necessary criteria for continuing the intended treatment. The members of both groups completed the resiliency scale. The morphine urinalysis test was also performed; the results were negative. The morphine test and the resiliency scale were also administered to the two groups after the intervention and four months later as follow up. The data analyses included the use of descriptive statistics, the chi-square test, and ANCOVA.

\section{Results}

Table 1 shows a chi-square test comparing the proportion of relapse between the two groups. As (Table 1) indicates, the proportion of relapse in the experimental group was $16.7 \%$ and $64.3 \%$ in the control group. The chisquare test of this difference was significant $\left(\chi^{2}=6.30\right.$, df $=1, P<0.001)$. An ANCOVA was further used to compare the effectiveness of lifestyle training on resiliency enhancement (Tables 2, Table 3). Both group were assessed at three different points, namely at pre-test, post-test and follow-up.

As the result in (Table 3) shows, there was a significant difference between the means of the two groups at posttest $(\mathrm{F}=33.76, P<0.001)$, with the post-test mean scores of the experimental group higher than that of the control group.

As the results in (Table 4) show, there was a significant difference between the means of the two groups at follow-up ( $\mathrm{F}=37.67, P<0.001$ ), with the follow-up mean scores of the experimental group higher than that for the control group.

\begin{tabular}{llll}
\hline \multicolumn{4}{l}{ Table 1. The Result of the Chi-Square between the Experimental and Control Groups } \\
\hline & No Relapse, No. $(\%)$ & Relapse, No. $(\%)$ & Total, No. $(\%)$ \\
\hline Experimental group & $10(83.3)$ & $2(16.7)$ & $12(100)$ \\
Control group & $5(35.7)$ & $9(64.3)$ & $14(100)$ \\
Total group & $15(57.7)$ & $11(42.3)$ & $26(100)$ \\
\hline
\end{tabular}




\begin{tabular}{lc}
\hline Table 2. Mean and Standard Deviation of Resiliency Scores at Different Stages & \\
\hline & Resiliency Scores, Mean \pm SD \\
\hline Pre-test & $56.33 \pm 8.51$ \\
$\quad$ Lifestyle training group & $52.93 \pm 5.43$ \\
$\quad$ Control group & \\
Post-test & $69.08 \pm 10.58$ \\
$\quad$ Lifestyle training group & $53.86 \pm 5.30$ \\
Control group & \\
Follow up & $68.83 \pm 9.76$ \\
$\quad$ Lifestyle training group & $52.43 \pm 5.13$ \\
Control group & \\
\hline
\end{tabular}

Table 3. ANCOVA Comparing the Resiliency of Post-Test Mean Scores of Experimental and Control Groups

\begin{tabular}{llllll}
\multicolumn{1}{l}{ Table 3. ANCOVA Comparing the Resiliency of Post-Test Mean Scores of Experimental and Control Groups } \\
\hline & SS $^{\mathbf{a}}$ & $\mathbf{d f}^{\mathbf{a}}$ & MS $^{\mathbf{a}}$ & F $^{\mathbf{b}}$ & 37.51 \\
Pre-test & 99.77 & 1 & 99.77 & 33.76 \\
Group & 89.63 & 1 & 89.64 & 0.001 \\
Error & 60.68 & 23 & 21.83 & \\
Total & 99475.00 & 26 & & \\
\hline
\end{tabular}

a Abbreviations: df, Degree of freedom; MS, Mean Square; SS, Sum of square

${ }^{\mathrm{b}}$ F,one way analysis of co-variance

\begin{tabular}{|c|c|c|c|c|c|}
\hline & SS $^{\mathrm{a}}$ & df $^{a}$ & MS $^{a}$ & $\mathbf{F}^{\mathbf{b}}$ & $P$ value \\
\hline Pre-test & 68.73 & 1 & 68.73 & 22.10 & 0.001 \\
\hline Group & 116.13 & 1 & 116.13 & 37.67 & 0.001 \\
\hline Error & 708.37 & 23 & 30.80 & & \\
\hline Total & 96728 & 26 & & & \\
\hline
\end{tabular}

${ }^{a}$ Abbreviations: df, Degree of freedom; MS, Mean Square; SS, Sum of square

${ }^{\mathrm{b}} \mathrm{F}$,one way analysis of co-variance

\section{Discussion}

The purpose of the present study was to investigate the effectiveness of lifestyle training for enhancing resiliency and the prevention of relapse for drug addicts. The findings show that the rate of relapse for the experimental lifestyle training group was significantly lower than that for the control group. The findings of this study correspond with those of Hodge et al. (15), Fromme and Orrick (16), Hodge et al. (17), Superina and Lingle (18), and Mcdermott et al. (19). Collectively, the findings of these studies imply that lifestyle adjustment can be effective in the prevention of relapse and the reduction of drug use after detoxification. Therefore during the life style training session it may be possible to prevent the relapse of substance use through such measures as: improving the client's skills in creating Healthy social networks and developing social relations with those friends and relatives with whom they had reduced or even lost their connections during the substance abuse period; introducing spirituality and spiritual coping mechanism; identifying the significant mistakes in one's life and correct those mistakes which can be an effective factor reducing the amount of substance abuse. Perhaps the reason for the effectiveness of lifestyle training is that it creates changes in the behaviors, thoughts, motivations, and ultimately the lifestyles of those who gave up drug abuse.

The second hypothesis of the present study was also verified, showing that lifestyle training also enhances resiliency in the experimental group. In other words, the experimental group's resiliency at the end of the instructional program and the follow-up stage had increased significantly compared with the control group. This finding corresponds with those of Valentine and Feinauer (20), Miller and Barret-Kruse (21), and Lev-wiesel (22). The result of this study showed that changing lifestyles contributes to resiliency. Lifestyle training enhanced resiliency by influencing the perception of surroundings, self-understanding, and how one confronts and solves important problems. The spiritual component was also one of the main elements of life enhancement resiliency by the virtue of its influence on dreams and objectives, belief in oneness, hope and optimism, perseverance, and inner control. Therefore, we can say that lifestyle training both directly and indirectly (through resiliency) causes people to resist drug abuse, thereby preventing relapse. Overall, the result of this study shows that lifestyle training prevents relapse and enhances resiliency in people after detoxification. The absence of female participants in the study, the low number of subjects, and the limited time of follow-up represent some limitations of the study. Future studies should therefore include both male and female subjects, use a longer follow-up period, and expand to disorders related to other drugs so that the results can be generalized to differing groups. 


\section{Acknowledgments}

We would like to thank the entire staff of the Aftab Population Center in Tehran, especially Mrs. Jafari who was a great help to our study.

\section{Financial Disclosure}

No financial disclosure is necessary.

\section{Funding/Support}

No support was provided.

\section{References}

1. Bishop FM. Managing addictions: cognitive, emotive, and behavioral techniques. illustrated, editor. USA: Jason Aronson, 2001; 2007.

2. Carroll KM, Nich C, Frankforter TL, Bisighini RM. Do patients change in the ways we intend? Assessing acquisition of coping skills among cocaine-dependent patients. J Psychological Assessment.1999;11(1):77.

3. Witkiewitz K, Marlatt GA. Relapse prevention for alcohol and drug problems: that was Zen, this is Tao. J Am Psychol. 2004;59(4):224-35.

4. Marlatt GA, Gordon JR. Relapse prevention: Maintenance strategies in the treatment of addictive behaviors. USA: The Guilford Press; 2005.

5. Carroll KM, Nich C, Sifry RL, Nuro KF, Frankforter TL, Ball SA, et al. A general system for evaluating therapist adherence and competence in psychotherapy research in the addictions. J Drug Alcohol Depend. 2000;57(3):225-38.

6. Zimmerman GL, Olsen CG, Bosworth MF. A 'stages of change' approach to helping patients change behavior. J Am Fam Physician. 2000;61(5):1409-16.

7. Laudet $A B$. The road to recovery: where are we going and how do we get there? Empirically driven conclusions and future directions for service development and research. Substance use \& misuse. 2008;43(12-13):2001-20.

8. LePage JP, Garcia-Rea EA. The association between healthy life- style behaviors and relapse rates in a homeless veteran population. $j$ drug and alcohol abuse. 2008;34(2):171-6.

9. Kitano MK, Lewis RB. Resilience and coping: implication for gifted children and youth at risk. Roeper Review. 2005;27(4):200-5.

10. Bogar CB, Hulse-Killacky D. Resiliency determinants and resiliency processes among female adult survivors of childhood sexual abuse. Journal of Counseling \& Development. 2006;84(3):318-27.

11. Gillespie BM, Chaboyer W, Wallis M, Grimbeek P. Resilience in the operating room: developing and testing of a resilience model. J Adv Nurs. 2007;59(4):427-38.

12. Connor KM, Davidson JR. Development of a new resilience scale: the Connor-Davidson Resilience Scale (CD-RISC). J Depress Anxiety. 2003;18(2):76-82.

13. Mohammadi M. Factors effective in resiliency in people at risk of substance abuse. Tehran: Welfare and Rehabilitation Sciences Tehran; 2005

14. Samani siamak JB, Sahragard N. Effects of resilience on mental health and life satisfaction. Iranian Journal of Psychiatry and Clinical Psychology. 2007.

15. Hodge DR, Cardenas P, Montoya H. Substance use: Spirituality and religious participation as protective factors among rural youths. Social Work Research. 2001;25(3):153-61.

16. Fromme K, Orrick D. The lifestyle management class: A harm reduction approach to college drinking. Addiction Research $\delta$ Theory. 2004;12(4):335-51.

17. Hodge DR, Andereck K, Montoya H. The Protective Influence of Spiritual ReligiousLifestyle Profiles on Tobacco Use, Alcohol Use, and Gambling. JSocial Work Research. 2007;31(4):211-9.

18. Suprina JS, Lingle JA. Overcoming Societal Discouragement: Gay Recovering Alcoholics' Perceptions of the Adlerian Life Tasks. J Individual Psychology. 2008;64(2).

19. Mcdermott L, Dobson A, Owen N. Determinants of continuity and change over 10 years in young women's smoking. Addiction. 2009;104(3):478-87.

20. Valentine LN, Feinauer LL. Resilience factors associated with female survivors of childhood sexual abuse. American Journal of Family Therapy. 1993;21(3):216-24.

21. Millern A, Barret-Kruse C. Four phases of Adlerian counseling: family resilience in action. J Indiv Psychol. 2002;58(3).

22. Lev-Wiesel R. Quality of life in adult survivors of childhood sexual abuse who have undergone therapy. Journal of Child Sexual Abuse. 2000;9(1):1-13. 